\title{
LA DIFUSIÓN DEL MAÍZ Y LAS TRANSFORMACIONES EN EL SISTEMA AGROPECUARIO DEL DOMINIO CISTERCIENSE DE ALCOBAÇA, SIGLOS XVIII Y XIX
}

\author{
ANTÓNIO VALÉRIO MADURO \\ Instituto Universitário da Maia, CEDTUR/CETRAD
}

\begin{abstract}
RESUMEN. El cultivo del maíz introdujo transformaciones profundas en la economía agropecuaria del dominio alcobacense. Analizamos el impacto de la redefinición de las áreas productivas; la prioridad dada al regadío y a las necesarias intervenciones de ingeniería hidráulica llevadas a cabo en los campos; la limitación impuesta al ganado de pastoreo y el desarrollo de la estabulación; la supresión de los cultivos tradicionales y la opción por nuevos criterios de asociación y rotación agrícola; la reestructuración del espacio del desgrane, secado, ensilado y molienda en función de la alteración del cereal dominante; así como la interferencia de la nueva planta al nivel de los foros y tributación y su impacto en la dieta alimentaria. La difusión del maíz tuvo al monasterio como parte interesada, algo que se puede constatar en la planificación de áreas de cultivo y en el empeño financiero necesario para realizar obras hidráulicas, por lo que su adhesión a la novedad es testimonio de la capacidad de rentabilización y mercantilización del dominio. La planta modificó el paisaje, amplió la producción interfiriendo positivamente en la sostenibilidad demográfica, aumentó las rentas y evidenció la capacidad de adaptación de la agricultura de Antiguo Régimen.
\end{abstract}

Palabras clave: maíz, pecuaria, tecnología agrícola, Císter, Alcobaça (Portugal).

\begin{abstract}
Maize production introduced deep changes in the mixed-farming economy of Alcobaça's territorial domain. We analyse the impact of the redefinition of the productive areas, the priority given to irrigation and the necessary interventions of hydraulic engineering carried out in the fields, the limit put on herding animals and the development of stockbreeding, the suppression of traditional crops and the option for new criteria of mixed crops and crop rotation, the restructuring of areas for grain threshing, drying, storage and grinding, depending on the
\end{abstract}

Recibido: 2-4-2018 • Aceptado: 29-6-2018 • avmaduro@gmail.com 
alteration of the dominant cereal, as well as the interference of the new plant in terms of rents and taxation and its impact on people's diets. The diffusion of maize was very important to the monastery as one can see in the planning of cultivation areas and in the financial commitment that was needed to carry out hydraulic works, hence the adherence to the novelty testifying the capability of commercialisation and of making the domain profitable. The plant modified the landscape, intensified production interfering positively in the demographic sustainability, increased rents and revealed the adaptation capacity of the Ancien Regime's agriculture.

Keywords: maize, mixed-farming, farming technology, Cister, Alcobaça (Portugal).

\section{Introducción}

En el curso de los siglos XVII y XVIII se establece en los territorios de los cotos cistercienses de Alcobaça un plan de reordenación agraria que puede calificarse de revolucionario. Por un lado, se cimentan y profundizan las viejas ventajas técnicas de la experiencia y el bagaje agrarios, a los que no es ajena la transfusión de otros saberes procedentes de los contactos y relaciones existentes entre las abadías portuguesas y extranjeras y, por otro, se difunde un modelo de explotación racional de la tierra permeable a la innovación, que garantiza la multiplicación de los frutos y la abundancia de la renta.

La gestión señorial y rentista del espacio no esquivará pues las inversiones directas, de la propia abadía, y las indirectas, especialmente a través de la figura de los grandes foreros, y todo con el fin de optimizar el sistema productivo, sea a través de la realización de obras de ingeniería hidráulica en las turberas o sea de roturaciones de matas para plantaciones extensivas de olivar, apropiándose para ello de un vasto territorio de incultos. Este sistema consigue casar a la perfección el desarrollo de los cultivos tradicionales - confiriéndoles escala de mercado- con la propagación de cultivos llegados del Nuevo Mundo, en particular del maíz, cultivado aquí bajo el sistema de regadío. La consiguiente transformación del paisaje agrario que ello implica, supone nos solo poner en práctica una política de atracción de colonos, sino también mantener un aumento demográfico ecológicamente sostenible, del que la nueva planta acaba incluso por ser causa y consecuencia, ya que la masa humana es esencial para responder a los crecientes quehaceres de la tierra.

Las directrices que estructuraron este nuevo complejo agropecuario, y que tomaron en cuenta al territorio alcobacense, pueden resumir en los siguientes elementos:

a) Definición de áreas de cultivo en función de la calidad del suelo, de la disponibilidad o no de recursos hídricos (secano versus regadío), de la adaptación de las plantas y su éxito productivo. 
b) Apropiación de espacios marginales al tratamiento agrícola (incultos) en el territorio serrano y litoral del dominio señorial, transformándolos en espacios productivos especializados al servicio de una economía de escala.

c) Dispersión del poblamiento y aumento de la población agrícola para responder a la intensificación de los cultivos sobre el territorio.

d) Retroceso del bosque caducifolio autóctono y de los terrenos de las ciénagas de la subsierra de Candeeiros gracias a la progresiva expansión del olivar monástico.

e) Inversiones por parte del monasterio y de los grandes foreros en el saneamiento, la innovación hidrotécnica y la valoración agrícola de las turberas de los campos de Maiorga, Valado dos Frades, Cela y Alfeizerão, con modificaciones en la conducción de los lechos fluviales, introducción de compuertas de marea para contener las aguas del mar y evitar la salinización de las tierras y el desarrollo de una red capilar de acequias que asiste a los cultivos regados y provee de energía a los molinos.

f) Expansión del monocultivo del pino en la zona litoral atendiendo a la necesidad creciente de maderas para obra civil y naval, leñas y fertilizantes, contrariando esta cobertura forestal el avance dunar y la acción nefasta del viento marítimo sobre los cultivos de regadío.

g) Intensificación del trabajo en las tierras de campo, con la adhesión a los nuevos cultivos agrícolas, principalmente el maíz, que se planta en asociación con leguminosas como el haba y en un detrimento del trigo y otros cereales.

h) Extinción de cultivos tradicionales como los millos miúdos en función de la progresiva expansión del maíz en las áreas de secano.

i) Introducción de nuevas rotaciones (con predominancia de los cereales de primavera/verano), regímenes de consolidación y alternancias de cultivos, de innovación de métodos y técnicas de trabajo de la tierra que permiten suprimir el barbecho y alcanzar el techo de la renta agrícola del Antiguo Régimen.

j) Apuesta por la irrigación de los cultivos herbáceos y huertos, por la racionalidad y el acompasamiento de la plantación y por el fin de la promiscuidad de cultivos entre viñedos, árboles frutales y cultivos herbáceos, en asociación con la prohibición de los cereales de paja; eso sí, salvo en las tierras de huertos y viñedos, la siembra de cebadas o alimpas (semillas de cereales de segunda resultantes del cribado) para verde o corte antes de espigar maíces y legumbres.

k) Asentamiento o ampliación de nuevos medios de transformación de lo producido a fin de dar salida al excedente de frutos, en el que se asegura, sobre todo en los 
lagares de aceite y vino y en las principales casas de molienda de la Orden, el régimen de explotación directa, así como el derecho de monopolio del monasterio sobre las aguas.

1) Reestructuración y redimensionamiento del espacio de desgranado, secado, ensilado y molienda, en función de la sustitución del cereal dominante, el trigo, por el maíz. Levantamiento de eras empedradas o de suelo de cal, pajares mayores y cilleros/casas de tullas o arcas, y de molinos pertrechados con un mayor número de piedras segundonas (para cereales de segunda, encabezados por el maíz), en detrimento de las piedras alberas o trigueras.

m) Desarrollo de la estabulación, como alternativa al ganado de pastoreo, debido a la limitación de los espacios de pasto y a la mayor disponibilidad de forraje (especialmente de cebadas para verde que preceden al maíz), lo que implica la producción de abonos y fertilizantes orgánicos de apoyo a la agricultura.

n) Aumento del ganado de yugo o de trabajo que asiste a las labores en las pequeñas explotaciones y de los aperos de tracción en función de la alteración del régimen de cultivo propiciada por el maíz.

o) Crecimiento de la renta agraria, sobre todo en el aceite y maíz, y refuerzo de la capacidad de mercantilización del dominio señorial.

Según los viajeros ilustrados que atravesaron las tierras de la comarca de Alcobaça, este panorama en materia agronómica, materializado en la domesticación de la naturaleza y la humanización del paisaje, sorprende por su profundo contraste con el cuadro que uno puede encontrarse en el resto de Portugal. Wiliam Morgan Kinsey, que visitó los cotos de Alcobaça en 1827, dio cuenta de esta capacidad de gestión y organización del espacio productivo, con declaraciones que se sitúan en la línea de lo relatado en su día por los aristócratas que le precedieron en el Grand Tour:

«The road hence to the Comarca town of Alcobaça led us through a wellcultivated country abounding with woods and green meadows, and producing large quantities of corn and great variety of fruits [...] The system of agriculture pursued in this district is excellent, and may beentirely attributed to the superior knowledge of Bernardine brethren in all matters connected with rural economy» (Kinsey, 1829, p. 440).

Este impulso a la explotación y rentabilización del suelo que acontece en Alcobaça, pero que también se siente en otras muchas comarcas y regiones de Portugal, revela, igualmente, la flexibilidad y la capacidad de adaptación del sistema señorial a los criterios de innovación técnicos que traen consigo los nuevos tiempos, garantizando 
de este modo la manutención de las viejas relaciones sociales y materiales de producción. Aunque es sabido que la transformación del tejido productivo puede en algunos casos desembocar en la degradación de los sistemas sociopolíticos y económicos y hacer surgir una organización social más apta para lidiar con la intensificación agrícola y los excedentes productivos, aquí las estructuras sociales preexistentes mostraron un elevado grado de resiliencia.

En Portugal, el trasplante de los cultivos del Nuevo Mundo, como es el caso del maíz, les permitió integrarse suavemente en el marco del sistema rentista señorial y en el de la autosuficiencia campesina gracias a su elevada productividad, contribuyendo de este modo a sentar las bases para una ocupación plena del territorio. El éxito del maíz fue total, vista su contribución decisiva a la supresión de las crisis cíclicas de subsistencia y carestías, o con sus repercusiones sobre el bienestar de la población campesina. Sin embargo, ese éxito nos muestra al mismo tiempo una vertiente anticapitalista, ya que, de alguna manera, ayudó a retrasar la estructuración y aparición de nuevos sistemas de trabajo y producción agrícola (Eiras Roel, 1998, p. 76). En todo caso, pasemos ahora a ver en detalle el ciclo de transformaciones y cambios que la nueva planta propició.

\section{La ordenación hidráulica y la difusión del maíz en las tierras de campo}

Las intervenciones monásticas en materia de ordenación hidráulica y en las labores agrícolas de los campos de Maiorga, Cela, Valado, Pederneira y Alfeizerão anteceden, con mucho, a la difusión del maíz en Portugal (Mapa 1). De hecho, el retroceso del mar y la reducción del tamaño de las lagunas de Pederneira y Alfeizerão favoreció las tentativas de secado y drenaje de los pantanos, desembocando en una reorientación de los lechos fluviales, la apertura de zanjas de drenaje y circulación de aguas, y la colocación de compuertas de marea para evitar los efectos del agua del mar (Mapa 1). Fray Fortunato de São Boaventura da cuenta de lo sucedido al respecto en el emplazamiento de Campo do Valado a Vasco de Pina, Alcaide Mayor y Proveedor del Monasterio en una fecha tan temprana como el 10 de septiembre de 1521 (Boaventura, 1827, p. 180). Y es que la política de concesión de tierras del monasterio incluía la obligación de roturarlas y cultivarlas, de limpiar las zanjas y taludes de los ríos y de mantener el espigón marítimo abierto (Natividade, 1960, pp. 106-109; Cordeiro, 2015, pp. 73-87; Maduro, 2013a, pp. 349-352; Maduro, Mascarenhas, Jorge, 2017, pp. 114-121).

Años más tarde, el Padre Carvalho da Costa nos describirá en 1712 el estado de las tierras de Campinho (Maiorga y Valado) y de los cultivos que allí se practican cuando nos dice que: 
Mapa 1. Cotos de Alcobaça, villas y medios de producción

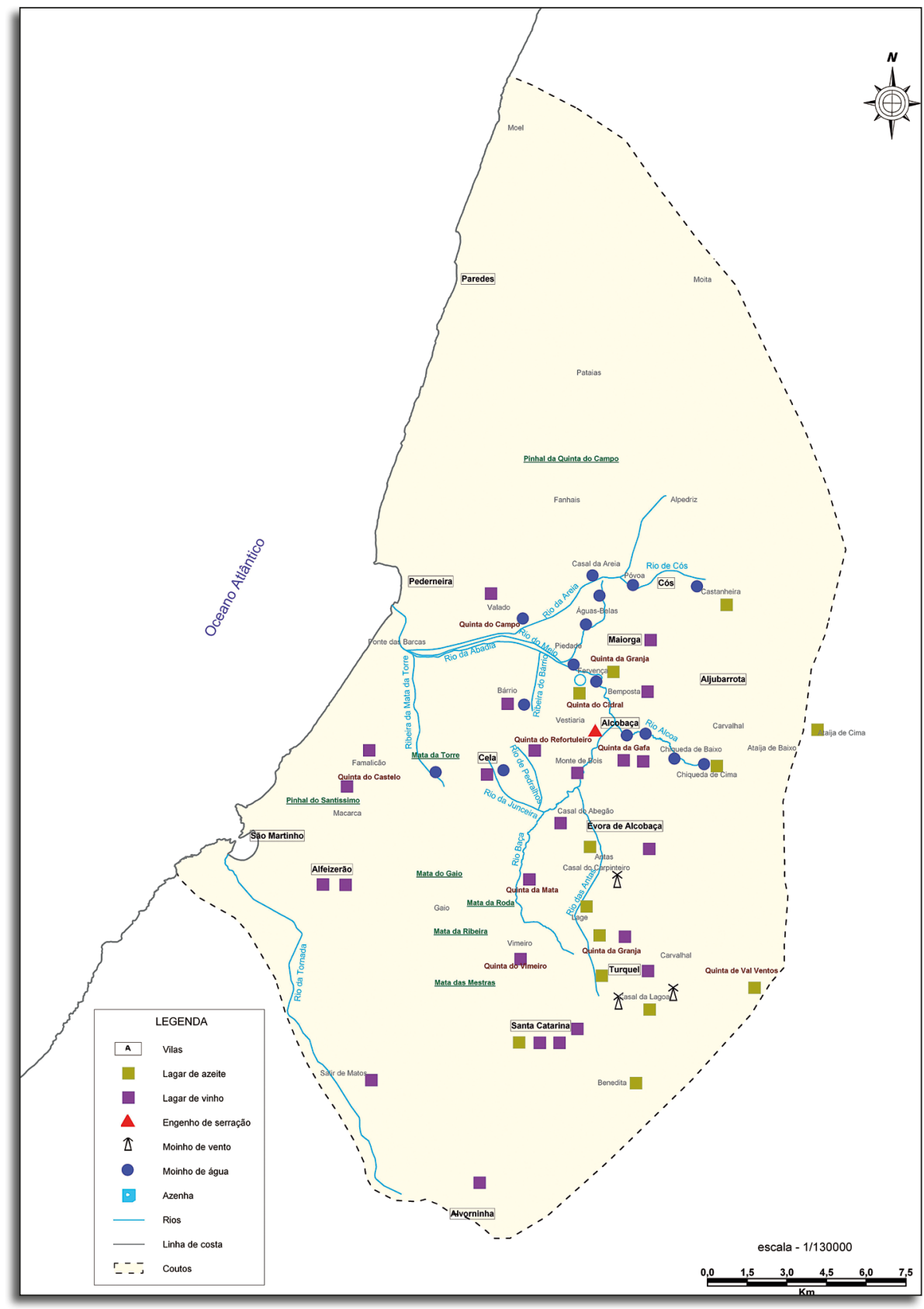


«tem hum campo muyto grande situado entre dous rios, o da Abbadia que passa por Alcobaça, \& o da Valla, os quaes fazem muytas innundaçoens a este campo, pelo meyo do qual correm dous rios pequenos, hum passa junto da estrada desta Villa, que vem de Aljubarrota, \& tem huma ponte de pè para passar a gente, que vem de Alcobaça; o outro vem da quinta do Paul, atravessando o campo o qual, nam sendo o anno invernoso, se semea quasi todo de trigo, \& havendo muy tascheas, se semea de milho, \& feijão, \& de toda a casta de legumes» (Costa, 1712, p. 133).

Por su parte, las Memórias Paroquiais de 1758 nos refieren que en los campos de Alfeizerão la tierra era abundante en maíz y haba, mientras que el nuevo cultivo del maíz no dejaba de ser responsabilizado de la degradación continua de los campos debido a la movilización excesiva de tierras y el riego constante que requería ${ }^{1}$. Ya en 1787, Fray Manuel de Figueiredo, en la respuesta dada a las Perguntas de Agricultura dirigidas aos Lavradores de Portugal ${ }^{2}$, encuesta elaborada por la Academia Real de Ciencias $(1787)^{3}$, rechazaba esta acusación argumentando que:

«com pouca razão querem muito atribuir a perda dos campos às sementeiras dos milhos grossos por estarem já quase no estado actual quando no século XVII principiara o milho grosso a ser semeado em Portugal e províncias do Sul, cresceram tanto as correntes das areias nos campos nomeados que todos os esforços do Mosteiro Donatário e povos fazendo muitas e repetidas aberturas pelas diligências do Mosteiro a não puderam remediar» (Maduro, 2013a, p. 349).

Sea como fuere, estas quejas son la expresión más clara de que el cultivo del maíz estaba ya presente en los antiguos campos inundados, situación, por cierto, muy parecida a la encontrada en otros lugares de la geografía portuguesa, y mismo peninsular, tal y como por ejemplo como nos informa Manuel Ardit a propósito «de las bonificaciones valencianas, en el Vinalipó o en Albufera de Valencia, o las catalanas del delta del Ebro» (Ardit, 2007, pp. 60-61).

Para evitar el avance de las dunas desde la costa, los monjes mandaron plantar un parapeto forestal de protección de pino bravo que, además de contener la arena, aplacaba los vientos y proveía de madera, leña y algunos rastrojos, indispensables para la agricultura (Mapa 2; Maduro, 2010, pp. 48-49). En el informe del Corregidor de Alcobaça de 1834, se puede leer a propósito de la posible destrucción del pinar que:

«o que he peor, é que estas areas e outras do lado de Pataias e Moita levádas pelos ventos nortes innundarião os ferteis campos da quinta do Valládo, Barquinha, e todo o valle que dalli se estende até Alfasirão, e Sam Martinho» (Maduro, 2017, p. 241).

Memórias Paroquiais (1758-1759), vol. II, 2010, p. 320.

Biblioteca Nacional de Portugal, códice 1490.

Perguntas de Agricultura dirigidas aos lavradores de Portugal, Academia Real de Ciências, 1787. 
Mapa 2. Carta hidrográfica del río de Casal da Areia (Maiorga), 1786

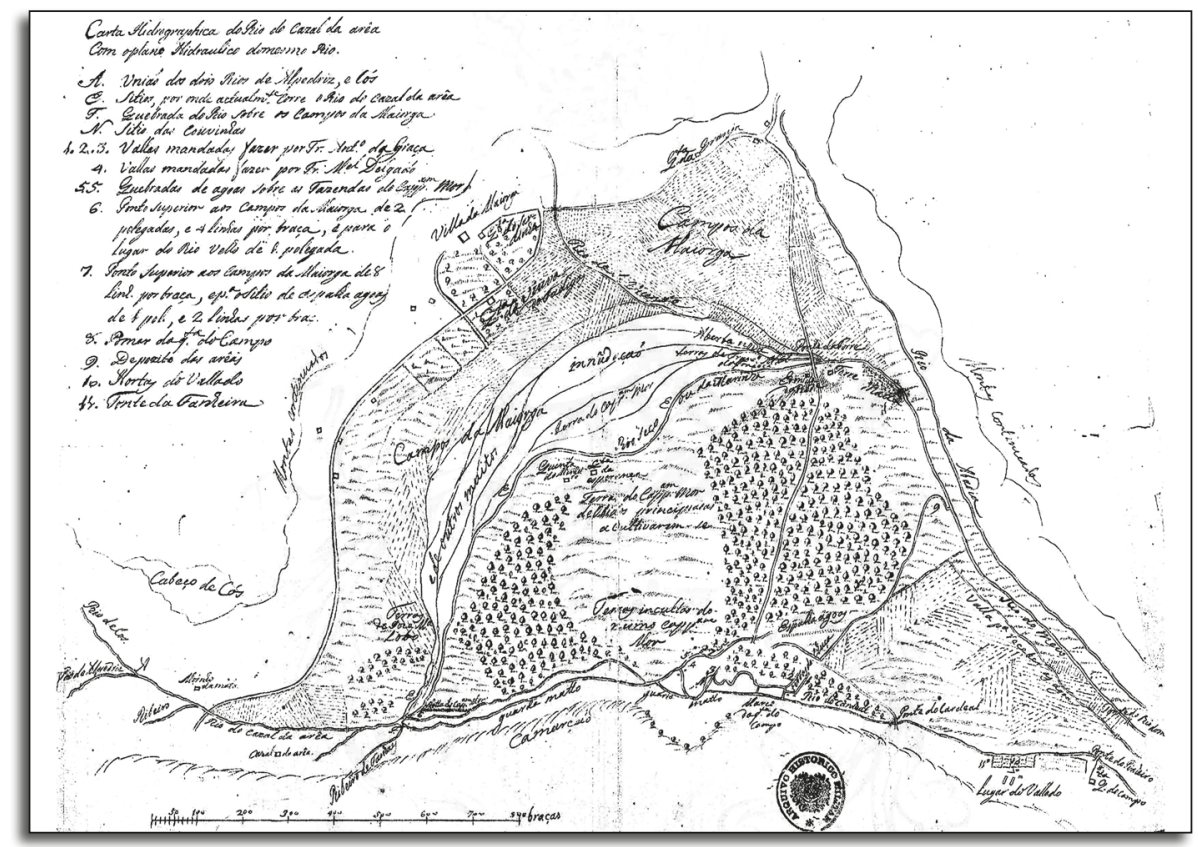

Fuente: Archivo Histórico Militar, DIV-4-1-14-05.

Regresando ahora al cronista Fray Manuel de Figueiredo, en la referida encuesta de la Academia de Ciencias (1787), donde se indaga «qual é o terreno próprio em que semeiam cada uma destas produções», no sorprende la respuesta dada, que «os Lavradores não fazem diferença de terrenos semeando só milhos e feijão nos campos, por serem impróprios para trigos, e cevadas pelas muitas ervagens que criam» (Maduro, 2013a, p. 342).

La cuestión del encenagamiento de los ríos, de la obstrucción de las zanjas de agua y del cierre del espigón del río de la Abadía (Mapa 3), constituyen no sólo un problema recurrente, sino que son materia de litigio continuo entre el monasterio donatario, los grandes foreros y los campesinos que cultivan las tierras (Maduro, 2011, pp. 176-177). Estos problemas de naturaleza hidrotécnica se deben al mal estado de una gran parte de las mencionadas tierras, siendo una de las causas de la depreciación que conoce la Quinta do Campo, la más extensa propiedad de los cotos abadiales, con 551 hectáreas, según el parecer y la evaluación realizada por los peritos en el momento en que se produce la extinción de las órdenes religiosas, en 1834: 
«Este magnifico Prédio [... ] não se acha em proporção com seu Valor e Rendimento, entre tanto estrago em que se achão as vallagens fosse mais piqueno, se os rios que lhe passão pelo meio the não amiaça peor ruínas fatais, fácil seria vendela pelo dobro do valor [...]» (Maduro, 2011, pp. 176-177).

En realidad, y como nos aclara Fray Manuel de Figueiredo, la intromisión regular de agua salada perjudicaba seriamente a los agricultores del término de Pederneira y Quinta do Campo, produciendo pérdida en los campos de Alfeizerão y São Martinho do Porto, lindantes con la bahía (Mapa 3). Para evitarlo, el único remedio posible consistiría en inundar estas tierras repetidamente con aguas dulces; ahora bien, dice Fray Manuel, si las mareas continúan con su intrusión, entonces, la única solución sería destinarlas a pastos (Maduro, 2013a, p. 339).

\section{El ciclo de cultivo del maíz}

\section{a) La cuestión del agua}

Como revelan las fuentes, el maíz se instaló de forma cómoda y preferente en los espacios beneficiados por los cursos de agua, lo que no implica que no se extendiese también hacia las áreas de secano, de menor beneficio productivo, e incluso, hacia las zonas montañosas de la serranía vecina ${ }^{4}$; un espacio cárstico este último, donde el maíz verdeaba en las tierras de felgar que anidaban en los estrechos valles, beneficiándose en los años de mayor estío del transporte de aguas proveniente de las lagunas permanentes que se distribuían a lo largo y ancho del vasto y extenso páramo.

A pesar de los problemas estructurales ya referidos, en cuanto a la circulación del agua, que podía poner en riesgo al conjunto de cultivos de la zona (Mapa 3), el aristócrata inglés William Beckford, que visita los cotos entre el 7 y el 11 de junio de 1794, se maravilla ante el buen orden agrícola que encuentra, declarando que «aqui tudo sorria; cada nesga de terra era aproveitada ao máximo, graças à perfeita compreensão e bom uso do sistema lombardo de irrigação» (Beckford, 1997, p. 92). Una alusión pone de manifiesto la intensificación del cultivo del suelo, así como, y según este autor, el conocimiento que el monasterio y sus colonos tenían de los secretos del riego perfeccionados en su día en la región de Lombardía. Al respecto, el mencionado Beckford había observado este mismo sistema de riego en el viaje que realizó a Italia en 1780, el cual describe en su obra, Italy; with Sketches of Spain and Portugal ${ }^{5}$. Por

\footnotetext{
$4 \quad$ El cultivo del maíz era frecuente a mediados del siglo XVIII en la Quinta de Val Ventos y en la Quinta de Turque, Arquivo Nacional da Torre do Tombo (en adelante ANTT), Livro de Despesas do Convento de Alcobaça, $n^{\circ} 5$ (1747-1750), mç 5, cx. 132.

$5 \quad$ Sobre la difusión de los sistemas de regadío, véase: Wolf, 1988, p. 113; Saltini, 2014.
} 
Mapa 3. Terrenos inundados de Cela, Valado, Pederneira y Famalicão

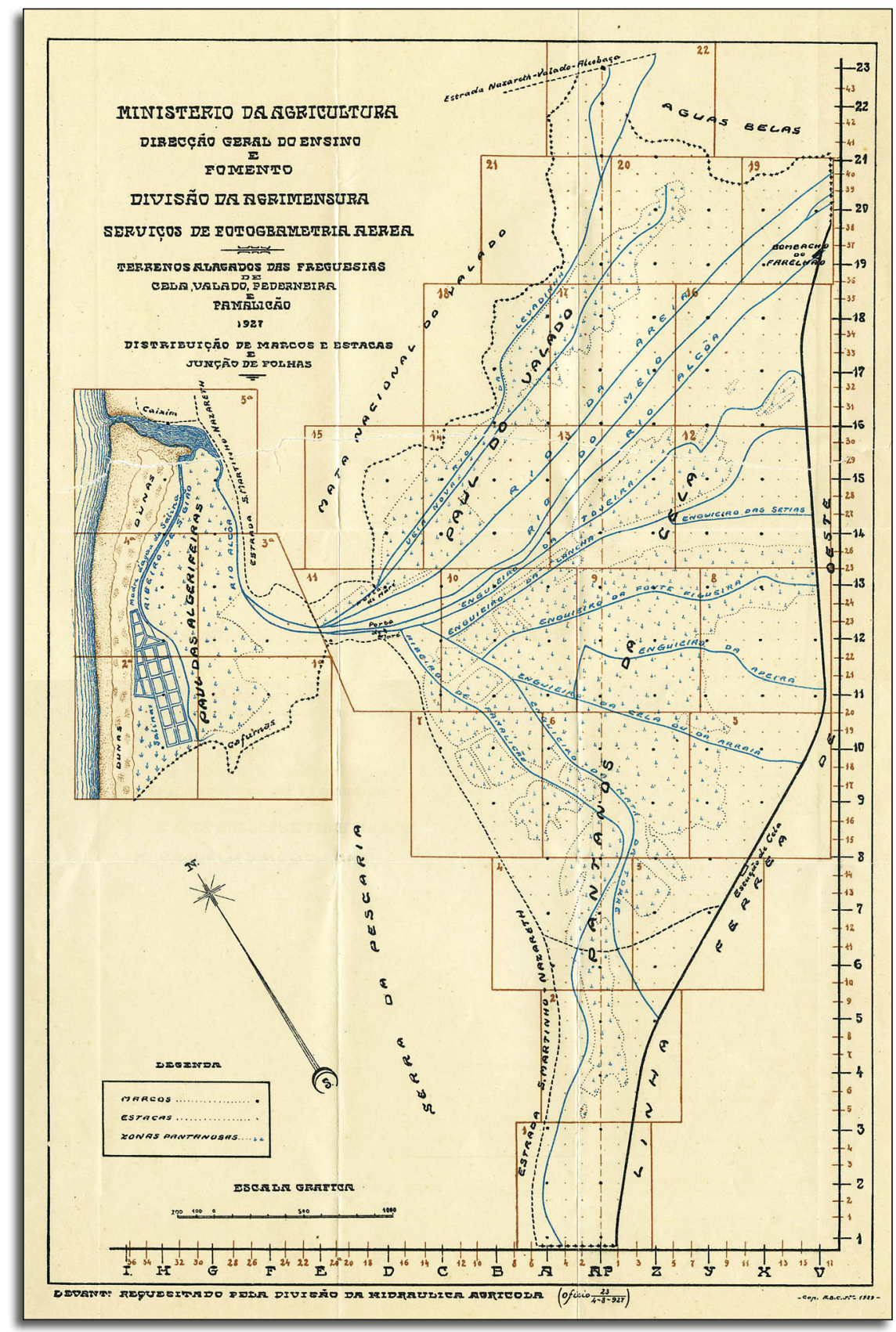

Fuente: Valença, 1927. 
lo demás, la utilización de las aguas para el riego de la huerta y el maíz entre los meses de mayo y septiembre conllevaba indemnizar a los molineros, ya que durante todo ese tiempo se inutilizaban total o parcialmente los ingenios de la molienda. A propósito de este asunto, las memorias parroquiales de la villa de Maiorga nos indican que:

«No tempo do Verão para se regarem os milhos com as agoas destes rios [refere-se ao rio da Abadia e ao rio da Areia] principalmente no campo paga cada lavrador aos moleyros certos alqueyres de pam cada qual conforme o tempo que occupe a agua para regar a sua seara» (Barbosa, Moreira, 2006, p. 166).

En las fuentes notariales abundan los contratos donde señala esta obligación. Por ejemplo, en el arrendamiento de un molino en la villa de Cós, en 1844, el propietario advierte al molinero «que nunca impedirá as aguaduras, e quando reconheça que por tal haja falta para trabalhar o moinho, lhe fará abatimento de um alqueire de milho por semana durante as regas $»^{6}$. En otros contratos, los propios molineros serán los usufructuarios directos del aforamiento de las aguas, situación que, por ejemplo, podemos apreciar en una escritura de 1852, en la cual se permite la utilización del agua canalizada que sirve al molino en el río Cabreiro, en Alpedriz, bajo pago de un alqueire (un cuarto de fanega) de maíz. Asimismo, se establece que la aplicación del riego sólo tendrá lugar los martes y sábados por la mañana durante los meses de mayo a septiembre ${ }^{7}$. En la misma línea, también suele acontecer que el propietario, a fin de no ver disminuida su renta, otorgue al molinero el derecho pleno sobre las aguas, con la salvaguarda de que, y como se puede ver en el contrato de un molino en Chiqueda, Prazeres de Aljubarrota, datado en 1863, los molineros «não poderão receber pelas aguaduras mais de uma oitava de grão por cada hora $[\ldots]\rangle^{8}$.

A fin de evitar tensiones y conflictos sociales, algunos propietarios cuyas tierras son atravesadas por zanjas de riego facilitarán la serventía a los demás regantes, tal y como puede verificarse en el contrato del Regulamento para o uso da água de regas establecido en 1887. En él, se autoriza el tránsito de las aguas del río Melas, en Póvoa de Cós, a través de un canal de regadío común, beneficiándose el primer otorgante del derecho de preferencia de riega de su propiedad, siempre y cuando efectúe los debidos reparos en la acequia ${ }^{9}$. Es usual también que los contratos consignen los derechos de

Archivo Distrital de Leiría, Cartório Notarial de Alcobaça, (en adelante ADL, CNA), $1^{\circ}$ of., lv. 8, fls. 79-80, 10 de noviembre de 1844 .

7 ADL, $C N A, 1^{\circ}$ of., lv. 1 f. 67,22 de agosto de 1852.

$8 \quad \mathrm{ADL}, C N A, 10^{\circ}$ of., lv. 42, fls. 61-62, 4 de julho de 1863.

$9 \quad \mathrm{ADL}, C N A, 10^{\circ}$ of., 1v. 81, fls. 80-82, 16 de julho de 1887. 
Tabla 1. Calendario del cultivo del maíz en los cotos de Alcobaça, siglos XVIII-XIX

\begin{tabular}{|c|c|c|}
\hline ENERO & ABRIL & MAYO \\
\hline Pago de foros y rentas & $\begin{array}{l}\text { Siembra de maíz «en los altos», precedida } \\
\text { por un cultivo de cebada para verde (tierras } \\
\text { de secano). } \\
\text { Escarda de maíces y legumbres, y desbaste } \\
\text { de la mies (secano). } \\
\text { Barbecho/labor de abrigo en las tierras de } \\
\text { campo/vega (tierras de regadío). }\end{array}$ & $\begin{array}{c}\text { Siembra del maíz, asociado con la } \\
\text { alubia blanca, con arados y trillos } \\
\text { en las tierras de campo (un cuarto } \\
\text { a medio alqueire de habas por un } \\
\text { alqueire de maíz) } \\
\text { Riego de los maíces. } \\
\text { Escarda del maíz y legumbres, y } \\
\text { desbaste de la mies (secano). } \\
\text { Mota o bina de los maíces y } \\
\text { legumbres, y segundo desbaste de la } \\
\text { mies (secano). }\end{array}$ \\
\hline JUNIO & JULIO & AGOSTO \\
\hline $\begin{array}{l}\text { Siembra del maíz, en asociación con la alubia } \\
\text { blanca, con arados y rastrillos en las tierras de } \\
\text { campo. } \\
\text { Riego de los maíces. } \\
\text { Escarda del maíz y legumbres, y desbaste de la } \\
\text { mies (regadío). } \\
\text { Adobo con majado verde/seco en hoyos. } \\
\text { Mota o bina de los maíces y legumbres, y } \\
\text { segundo desbaste de la mies (regadío). }\end{array}$ & $\begin{array}{l}\text { Siembra del maíz, en asociación con la } \\
\text { alubia blanca, con arados y trillos en las } \\
\text { tierras de campo. } \\
\text { Riego de los maíces. } \\
\text { Escarda del maíz y legumbres, y desbaste } \\
\text { de la mies (regadío). } \\
\text { Adobo con majado verde/seco en hoyos. } \\
\text { Mota o bina de los maíces y legumbres, y } \\
\text { segundo desbaste de la mies (regadío). }\end{array}$ & $\begin{array}{c}\text { Siega del maíz de los altos. } \\
\text { Riego de los maíces. } \\
\text { Mota o bina de los maíces y } \\
\text { legumbres, y segundo desbaste de la } \\
\text { mies (regadío). }\end{array}$ \\
\hline SEPTIEMBRE & OCTUBRE & NOVIEMBRE \\
\hline $\begin{array}{c}\text { Siega del maíz de los altos. } \\
\text { Desgrane del maíz en la era. } \\
\text { Riego de los maíces. } \\
\text { Pago de foros y rentas (Natividad, día 8; S. } \\
\text { Miguel, día 29). }\end{array}$ & $\begin{array}{l}\text { Siega del maíz y de la alubia en las tierras } \\
\text { de campo. } \\
\text { Desgrane del maíz en la era. } \\
\text { Pajas de la alubia y del maíz para pienso } \\
\text { del ganado. } \\
\text { Pago de foros y rentas de maíz y alubia (S. } \\
\text { Simón, día } 28 \text { ). }\end{array}$ & $\begin{array}{l}\text { Pago de foros y rentas (Todos los } \\
\text { Santos, día 1; San Andrés, día 30). }\end{array}$ \\
\hline
\end{tabular}

Fuente: Perguntas de Agricultura dirigidas aos lavradores de Portugal, Academia Real de Ciências, 1787; Biblioteca Nacional de Portugal, códice 1490; contratos agrarios diversos.

serventía a las «águas de pé e de carro», como se puede apreciar en los contratos de compra de serventías en las de Quinta do Campo ${ }^{10}$.

Pero no siempre los asuntos del agua se resolvían a satisfacción de todos, tanto por las regalías de los privilegiados, como por la falta de respeto a los derechos de

$10 \quad$ ADL, $C N A, 1^{\circ}$ of., lv. 93, fls. 15-16, 16-17, 18-19, 10 de maio de 1891. 
serventía establecidos por los usos y costumbres, lo que implicaba desvíos y robos del cupo de los vecinos. Eran situaciones recurrentes que ampliaban, y amplían aun hoy, los niveles de violencia en las comunidades rurales (O’Neil, 1984, p. 193; Wateau, 2000, pp. 163-164; Ardit, 2007, p. 65). De hecho, los usos y abusos del agua para riego, o como fuente de energía, se destacan en las actas municipales, y a ellos se oponían los vecinos a propósito de la construcción de molinos, la instalación o elevación de presas o la colocación de cubos de riego en las terrazas de los ríos (Maduro, 2011, p. 254).

\section{b) Barbecho, siembra, escarda y bina}

La tierra de siembra del maíz se beneficiaba generalmente de la práctica del barbecho, de ese período de reposo de la tierra que se daba entre la primera labra y la siembra. Se la podía dejar en barbecho a secano o también después de las primeras lluvias. Gracias a esta operación se limpiaba el suelo de malas hierbas y se aumentaba su capacidad hídrica. En algunos contratos de alquiler encontramos consignada esta obligación, como en el caso del arrendamiento de la Quinta de Santa Ana, en Alcobaça, en 1822, en el cual el «rendeiro sera obrigado a deixar de alqueve de milho seis geiras de terra no ultimoanno do seu arrendamento ${ }^{11}$. Asimismo, en el alquiler de una tierra de pan en Vimeiro, en 1854, donde se manda dejar «a terra no fim do arrendamento toda de restolho de milho, ou alqueváda $[\ldots]\rangle^{12}$.

Como explica Fray Manuel de Figueiredo en 1787, la selección de semillas era aleatoria, aunque había quien se reservaba las mazorcas de mayor tamaño como simiente, pero en uno u otro caso el agricultor procuraba no repetir terreno de cultivo para el maíz, a fin de no cansarlo:

«Não há método algum para escolher sementes. A maior parte dos seareiros recebem as sementes das tulhas do Mosteiro, e dos seus rendeiros, que as dão como o ano antecedente as produziu. Os que podem, não semeiam na mesma terra o que esta produz. E usam nisso utilidade mudando as sementes».

En cuanto a los criterios de preparación del suelo hasta la llegada de la siembra, a finales del siglo XVIII, se constata que los bueyes eran preferidos a los caballos, al contrario de lo que sucedía en muchos ámbitos de la agricultura europea, (Bath, 1983, pp. 65-67, 288-292; Heers, 1965, pp. 29-30).

«O preparo das terras para os géneros temporões é lavrando primeiro, semeando, e depois regando, e fazendo estes trabalhos em altura de um palmo para milhos nos 
altos. Lavram, e deixam estar a terra um mês, e mais, a que eles chamam abafar; tornam a lavrar, semeiam, e depois gradam com bois, ou cavalos que fazem trabalho mais breves, e ruim pelos movimentos apressados que os dos bois, deixarem inteiros os torrões em que topam, pelo saltar a grade com os mesmos movimentos mais apressados» (Maduro, 2013a, p. 342).

La siembra del cereal, realizada preferentemente durante el creciente lunar, se podía hacer en surco o en hilera, y hasta en pequeñas parcelas de huerta familiar, en hoyos. El maíz entraba entonces en régimen de asociación con la judía blanca en una proporción estimada de entre $1 / 4$ a $1 / 2$ alqueire de alubia por uno de maíz, era lo que las gentes designaban «sembrar a la envidia». Para acomodar el cereal y aplanar la tierra se le daban dos vueltas de rastrillo, la segunda de raso o del revés, utilizándose en algunas tierras barrosas el mazo de desterronar para deshacer los terrones que habían escapado a la acción del rastrillo (Dias, 1993, pp. 369 y 371).

Sobre los fertilizantes utilizados para beneficiar los cultivos, se constata la carencia de rastrojos por la ocupación de los incultos para fines agrícolas, aunque sabemos que por cada hectárea de tierra cultivada era necesaria una provisión de unas ocho hectáreas de ese rastrojo (Estabrook, 1988). Además de los abonos procedentes de los establos del ganado, algunos labradores utilizaban también las algas que las mareas arrastraban hasta la costa.

Por su parte, el empleo de cangrejos - los llamados pilados - capturados por pescadores como abono para los maizales — para una yugada de regadío sabemos se utilizaba una carretada de bueyes - , sólo se difunde como tal a partir de mediados del siglo XIX (Ribeiro, Lautensach, Daveau, 1991, p. 1219). En todo caso, un tema en el que, una vez más, Fray Manuel de Figueiredo viene en nuestra ayuda al mencionarnos los fertilizantes utilizados en el abonado a finales del siglo XVIII:

«Como nesta comarca há falta de matos não poder haver abundância de estrumes, e sem estes produzem a maior parte das terras, que produziriam mais, se fossem bem estrumadas, como vemos em outras, que os Lavradores adubam com bons estercos. Não é conhecida a causa de produzirem sem estrumes as terras desta Comarca. Não usam os Lavradores desta Comarca de misturas de terras, e lançam nestas todos os estrumes, que podem adquirir [...] com a declaração que o bagaço é o de uva, por guardarem o das azeitonas para os porcos. Os Lavradores das terras de São Martinho lançam às terras todo o lixo, que o mar lança nas margens da mesma baía, e fora desta, que vem misturado com espadana quase vermelha. Os matos de que usam para estrumes são tojos misturados com outros arbustos com ramas de pinheiro que lançam a curtir nas estradas, e cortes. Os Lavradores trazem os gados pelas terras, e lhe deitam os estercos das estradas e currais. O Marne de todo desconhecem os Lavradores, e só alguns ouviram falar nele depois que principiou a usar dele o Sr. da Fábrica de Vidro da Marinha Grande» (Maduro, 2013a, p. 341). 
Entre los cereales, el maíz er la única planta que se beneficiaba de la escarda, operación recurrente en cambio en las verduras de la huerta (Ribeiro, 1986, p. 116). Una tarea que buscaba liberar el cultivo de las hierbas dañinas, retirar las plantas y mejorar el efecto del riego. Entre dos semanas y un mes después, la mota o bina que le seguía facilitaba en cambio la provisión de pasto para los animales.

\section{c) Los obstáculos naturales al éxito del maíz}

Instados por el cuestionario de la Academia de Ciencias a responder sobre los daños que la competición de las malas hierbas y los animales provocaban en las mieses, y a qué remedios se echaba mano para resolver todos estos males, los contemporáneos nos aclaran en 1787 que:

«Só os pássaros fazem dano nas searas; e os texugos nos milhos. A ervilhaca, e o joio são as ervas mais nocivas nas searas; e também tiram a substância das terras o escalracho, marcela, e outras ervas anónimas. Para afugentarem os pássaros das searas usam os lavradores de espantalhos, e os mandam enxotar por seus filhos menores com matracas de pena, e pau, vozeando amiúde, o que também fazem para acautelar a entrada de texugos nos milhos» (Maduro, 2013a, p. 341).

También sabemos que para repeler a los predadores naturales, a los pájaros sobre todo, los mozos eran responsabilizados de la guarda y vigilancia de los maizales y que, cuando era menester, los recorrían dando alaridos, golpeando latas, lanzando bombas o quemando cortezas de pino para alejarlos. Asimismo, se colocaban espantapájaros sonoros al objeto de ahuyentar tanto a los mencionados pájaros como a los tejones, ginetas, hurones y zorros, que se deleitaban con las espigas maduras (Ribeiro, 1928, pp. 57, 163).

El maíz también era acometido por plagas. Las procesiones religiosas realizadas para espantar la «bicha» de los campos — nombre por el que era conocida la oruga del maíz (mythinma unipuncta)_, que hacía acto de presencia en los campos en el mes de mayo, era un acto que formaba parte de las manifestaciones rituales de bendición de la planta y del exorcismo de las plagas (Natividade, 1916, p. 107). En el mismo sentido, las rogativas de mayo constituían en años de sequía una llamada a las lluvias con el objetivo de que éstas facilitasen el desarrollo del cereal. No obstante, el humor de las estaciones dotaba a la agricultura de un amplio grado de imprevisibilidad, por lo que la cosecha podía ser avara o abundante. Fray Manuel de Figueiredo destaca precisamente como uno de los factores más lesivos del año agrícola «os rigores ou desigualdades das Estações». Y en la respuesta otorgada a la demanda de la Academia de Ciencias sobre los agentes de destrucción, como «neves, geadas, pedras» [nieves, heladas, granizo], elucidaba que: 
«não caiem neves na Comarca de Alcobaça. As geadas só danificam as árvores de espinho, e plantas das hortas. O pedraço de trovoadas do Estio, que raríssimas vezes é prejudicial aos frutos desta Comarca, caindo depois do fim de Julho, só danifica milhos, vinhos, feijões, frutas, hortas e meloais, por estarem já segados trigos, cevadas, e o pouco centeio que produz este distrito. O pedraço de inverno raras vezes faz prejuízo nesta Comarca» (Maduro, 2013a, p. 258).

\section{d) Las transformaciones en los sistemas de desgranado, ensilado y molienda del maíz}

El maíz provocó transformaciones considerables al propiciar la sustitución de cultivos, la introducción de nuevas rotaciones y asociaciones de plantas, la obtención de altos rendimientos o al alterar la estructura pecuaria, pero también al dar lugar a la aparición de nuevos espacios de guarda de semillas, de aparatos tecnológicos y de instrumental de trabajo empleado en el desgranado de las mazorcas. Todos estos cambios, como anota Pegerto Saavedra, contribuyeron a una desestructuración efectiva del agrosistema tradicional imperante hasta entonces, el cual, naturalmente, tuvo que sufrir después un proceso de autorregulación (Saavedra, 2010, p. 111).

La llegada y asentamiento de la planta significó que se modificaron las eras y los aperos de desgranado, y que crecieron los silos, los graneros y las huchas donde se almacenaba el grano una vez seco y limpio. La sustitución del cereal dominante, del trigo, por el maíz, dio lugar asimismo a una alteración sustantiva del recinto de desgranado, que ahora requería de un espacio amplio dedicado al secado (Caldas, 1998, p. 177). Las eras redondas de tierra batida, características del universo cultural mediterráneo donde predominaba el cultivo de los cereales, en general, y del trigo, en particular, y la trilla era realizada con ganado bovino y mular y trillos, no se dan aquí, en el área atlántica, donde las citadas eras eran cuadrangulares, con piso de losas de piedra o amasado de cal, y en las que el desgranado se efectuaba a fuerza de brazos con la ayuda de mayales (Dias, Oliveira, Galhano, 1994, pp. 25-32).

Encontramos este rediseño funcional de las estructuras de secado y desgranado en la Quinta cisterciense de Val Ventos ya en el siglo XVIII, donde había una edificación que poseía 18 metros de largo por 20 de ancho y un muro de cantería que impedía la dispersión de las semillas ante el violento ejercicio de la maya. Pero también, en la granja medieval — bautizada recientemente como Quinta do Campo-, se levantó en el mismo siglo XVIII una era cuadrangular para dar salida a la enorme cantidad de frutos que el maíz producía.

Estas alteraciones no sólo se registran en las grandes unidades agrarias de los cotos, como las Quintas, sino que también se dieron en el marco del universo campesino. En este sentido, Jorge Dias y sus colaboradores consideran que los distritos de Coimbra y Leiría, y del que la comarca de Alcobaça formaba parte, integrarían un área de confluencia entre dos civilizaciones agrarias: una más antigua, situada al sur y 
enraizada en la agricultura extensiva del trigo, y otra, en formación durante los siglos XVII y XVIII, localizadas en las regiones del norte, que acabará asentada sobre la agricultura intensiva del maíz (Dias, Oliveira, Galhano, 1994, p. 28). Curiosamente, estos estudiosos nos advierten del aparente desorden tipológico que sería propio de una zona de frontera, pero también de la existencia de un régimen de policultivo, visto que, incluso en las áreas de secano, es posible encontrar el maíz en los pequeños huertos de las casas campesinas en colaboración con las habas, las calabazas y las hortalizas. Así, en función del espacio útil disponible y de la falta de respecto a las convenciones sociales de la época, los campesinos levantaban eras cuadradas, rectangulares, trapezoidales, circulares, con uno, dos o tres cantos, poligonales (Garcia, 1986, p. 64). En relación con ello, los contratos agrarios de la zona, haciéndose eco de las exigencias de la agricultura intensiva del nuevo cereal, llegaron a incluir entre sus cláusulas la obligación de asentar una era permanente en la explotación. Esto es lo que se aprecia, por ejemplo, en las disposiciones que forman parte del arrendamiento de una hacienda en la villa de Maiorga en 1884 por un período de nueve años a cambio de una renta de 180 alqueires de maíz, ya que en él que se establecía que el arrendador hiciese «...uma eira de cal na qual se possam seccar simultaneamente cincoenta alqueires de milho» ${ }^{13}$.

Cambió el cultivo y cambiaron, como ya referimos, los métodos de desgranado de la planta. El mayal, apero inicialmente asociado a la geografía cultural del centeno, empleado debido a la mayor dificultad de este cereal para soltar el grano, es prontamente adoptado para el desgrane del maíz (Carvalho, 1953, pp. 340-341 y 353; Dias, 1993, pp. 336-337 y 345-346; Oliveira, Galhano, Pereira, 1983, pp. 295-296). Fray Manuel de Figueiredo nos refiere en 1787 que: «Para debulhar usam de cavalos, bois (cereais de pragana), e manguais que é o instrumento, com que debulham todos os milhos grossos (e também os feijões)» (Maduro, 2013a, p. 342). La maya del maíz pasa así a integrarse en el ciclo de trabajos colectivos y recíprocos, en el «comercio brazal» entre los vecinos, designado comúnmente como los «trabajos de merecer» o «dias cambiados», que van asociados a un gran número de tareas en el mundo rural, como el pasto de los ganados en común; las rozas de matas para abonado de los campos; la cesión de bueyes o de ganado bovino, esencial para labores como desempedrar, labrar y trillar, las escardas, cavas, binas y deshojes del maíz; las vendimias y la recogida de la aceituna; etc. Todos ellos trabajos diversos que hacen de la aldea un espacio cooperativo en la producción de alimentos y subsistencias. Solo en las pequeñas explotaciones agrícolas, en las que la era estaba ausente ante falta de recursos materiales, el maíz se desgranaba manualmente gracias al pico de deshojar, un instrumento que facilitaba la extracción de la primera capa del maíz (Carvalho, 1953, p. 80; Oliveira, Galhano, Pereira, 1983, p. 314). 
Con la progresiva expansión de la planta y las dificultades de su desgranado tardío en relación al calendario agrícola, comienzan a importarse los hórreos del noroeste peninsular. Éstos, que conservan y protegen a las mazorcas ya deshojadas de las humedades, llegan a Alcobaça, en versión simplificada en los albores del siglo XX. La propagación de los hórreos, fijos o móviles a fin de aprovechar la orientación solar, es prácticamente exclusiva de las tierras de Maiorga, Cela, Valado, Alfeizerão y São Martinho.

La buena condición del maíz con el que se pagaban los foros y rentas de los molinos preocupaba a los propietarios, quienes exigían que fuesen de un cereal «bom, limpo e capas de receber conforme o receber das maquias» ${ }^{14}$, siendo obligatorio además que fuese de la tierra, es decir, de la presente cosecha y no del guardado en el granero $^{15}$. Las mismas exigencias pueden verse en el arrendamiento de una vega del Real Colegio en 1807, precisándose en él que el maíz sea de la tierra, bueno, limpio y capaz de ser recibido por el San Miguel de septiembre ${ }^{16}$.

Respondiendo a la cuestión de la Academia de Ciencias relativa a la guarda y conservación de los cereales, Fray Manuel de Figueiredo nos informa en 1787 de que en la comarca de Alcobaça:

«Os pobres guardam os géneros nas suas arcas; e os ricos nos seus celeiros, em que não há regra que possa fazer exemplo. Uns celeiros são térreos, o pavimento de pedra ou tijolo. Outros celeiros são altos e de sobrado de madeira de pinho ou de argamassa assente sobre o solo» (Maduro, 2013a, p. 343).

En las granjas y quintas cistercienses los silos solían ocupar, por norma, el primer piso, dejando el bajo, más fresco, para almacén del aceite, que se conservaba en cubas de mármol. Por su parte, los campesinos construían en sus casas dependencias dedicadas a la guarda de las cubas y grano, haciendo en este último caso que una de las estancias funcionase como granero, para lo que se encalaba con la intención de que así se regulase la temperatura y se conservasen los géneros.

El cereal acumulado en el monasterio era paleado regularmente a fin de preservar su calidad. El principal problema consistía en defenderlo de los ratones, pájaros y plagas, como la del gorgojo. Los silos, al igual que los molinos, tenían a veces una gatera para el felino que se encargaba de custodiarlo frente a la acción de aves y roedores. El arca y el arcón de madera de pino con tapa, para impedir el acceso a los ratones y hurones, se lavaban anualmente con agua y vinagre para que la madera

ADL, $C N A, 1^{\circ}$ of., lv. 8, fl. 80, 12 de abril de 1840 .

ADL, $C N A, 4^{\circ}$ of., lv. 34, fls. 61-62, 7 de junho de 1830 .

ADL, $C N A, 1^{\circ}$ of., lv. 62, fls. 42-43, 43-45, 8 de novembro de 1807. 
rechazase una posible invasión del gorgojo. El citado Fray Manuel de Figueiredo nos refiere al respecto que:

«contra o gorgulho usam folhas de figueira-do-inferno, [planta que se sabe dotada de propriedades como repelente de insetos e bactericidas], e outros preservativos, em que creio pouco, como nas cabeças de pescadas bem secas e penduradas nas paredes dos celeiros que dizem (eu nunca vi) fazer fugir o tal gorgulho em carreirões pelas portas e frestas dos celeiros» (Maduro, 2013a, p. 343).

La continua y abundante producción de maíz, que destronó al trigo, conllevó la aparición de alteraciones en las muelas que equipaban a los molinos, conduciendo al predominio de las parejas de piedras segundonas — para los cereales de segundafrente a las llamadas alberas o trigueras. Basta en este sentido con mencionar que la renta obtenida en dos molinos que el monasterio detentaba en la villa de Alcobaça se estimaba en el año de 1835 en 1.160 alqueires de maíz, estando el trigo excluido de este foro, lo que por sí ya es bastante significativo de lo dicho sobre su paso a un muy segundo plano ${ }^{17}$. En el vecino municipio de Caldas da Rainha, tenemos noticias más precisas sobre la relación que existía entre piedras empleadas para los cereales de primera y de segunda en los molinos de viento y de agua. Así sabemos que en el motor eólico 86 eran segunderas (80,4\%) y 21 alberas $(19,6 \%)$, y en el hidráulico 39 eran segunderas $(81,2 \%)$ y 9 alberas $(18,8 \%)^{18}$.

Con la llegada del maíz se verifica igualmente una reforma de las unidades que permiten la multiplicación de los frutos, fundamentalmente mediante la ampliación y el levantamiento de represas, el refuerzo de la maquinaria de rueda de los molinos en una o dos piedras o la transformación integral del aparato motor de los mismos en función de su potencia, convirtiendo así el viejo y clásico molino de agua en una aceña. A estos cambios y mejoras introducidas en el equipamiento protoindustrial se suma, sobre todo a partir de la extinción de las órdenes religiosas y del fin del monopolio sobre las aguas y los ingenios de producción que éstas tenían, una democratización de las unidades hidráulicas y eólicas que plagaban los ríos y las cumbres de los montes. Bastaría con decir que según un informe municipal de 1839, la comarca de Alcobaça poseía «57 moinhos de manufacturar cereaes, sendo 40 de agua, e 17 de vento» y que en 1862 se registraban en ella 159 molinos de agua y 85 de viento. Es decir, que en esos veintitrés años el sistema hidráulico se había multiplicado por cuatro y el eólico por cinco (Maduro, Mascarenhas, Jorge, 2017, p. 112).

17 ADL, Governo Civil, (en adelante ADL, GC), $1^{a}$ Repartição-Ministérios, cx. 1 (1835-1857).

18 ADL, GC, Atividades Económicas, Agricultura, cx. 12 (1876-1912). Declarações sobre o estado dos moinhos de farinha no concelho de Caldas da Rainha em 1884, dando cumprimento ao Regulamento de 30 de Junho de 1884. 


\section{La productividad del maíz y los foros}

Como ha destacado Gaetano Forni, la combinación del arado y la llegada y asentamiento del maíz en Europa provocó un boom productivo y demográfico que facilitaría la emergencia de la sociedad industrial (Forni, 1993, p. 263). Su cultivo fue considerado milagroso, si bien, en principio, las resistencias al mismo situaron a la planta en la categoría de forraje de animales, sólo después el pueblo lo adoptó en los campos y lo integró en su dieta alimentaria (Flandrin et Montanari, 2001, p. 149). En realidad, la peregrinación inicial del maíz por el espacio peninsular a lo largo del siglo XVI no habría pasado de ser un experimento y una curiosidad cultural si no fuese por este hecho (Pérez García, 1990, p. 82).

José Veríssimo da Silva, nos advierte de que la introducción de las naranjas y el maíz salvaron, en gran medida, a la agricultura portuguesa (Silva, 1815, p. 242). Igualmente, Duarte Ribeiro de Macedo considera una hazaña singular la actuación de la persona que trajo la planta de Cádiz a Coimbra, insistiendo en «que não he fácil de explicar a abundancia, utilidade, e riqueza, que se seguio ao Reino desta rustica curiosidade de hum particular» (Macedo, 1817, pp. 117-118). En todo caso, su productividad frente a la de los otros cultivos cerealeros tradicionales bastó para convencer a sus detractores, al tiempo que sirvió también para poner de manifiesto la capacidad de adaptación del sistema agrario señorial a las innovaciones. Los autores del siglo XVIII dan cuenta de que la producción que rendía el maíz en años de normalidad climática era la esperada frente a la de los otros cereales y leguminosas:

«São a maior parte das terras férteis, e nos anos regulares a sementeira de um alqueire de trigo produz de sete até oito alqueires; de milho, de trinta até 32; de cevada, de vinte e oito até trinta; de feijão branco de dez até doze; de favas, de seis até sete; e à proporção dos mais legumes». Referindo-se à saúde agrícola da comarca, acrescenta ainda o monge que a comarca: «produz com abundância azeite, frutas que aqui chamam de Caroço, feijão branco, cevada, tremoços, trigo, e vinho. Também é muito o milho grosso, que às vezes sobe a preço caro, por ser o género de que mais se sustentam estes povos» (Maduro, 2013a, p. 339).

Pero como ha destacado Eiras Roel, «la eficacia del maíz no debe contemplarse solamente en términos de productividad por hectárea, sino conjuntamente en términos de frecuencia de cultivo y de intensificación agraria», situación ésta que implica una evaluación seria de las condiciones previas que aseguran la difusión y fertilidad de la planta (Eiras Roel, 1998, p. 52). En relación con esto, por ejemplo, la victoria del maíz no sólo se caracterizaría por la reducción de la presencia del trigo y centeno en las rotaciones agrarias, o sea, por la proclamación de una victoria de los cereales de 
primavera/verano sobre los de invierno - el mijo y otros maíces menudos a los que, en portugués, la nueva planta va a robar el nombre-(Caldas, 1998, p. 177; Rocha, 1998, p. 34; Fariña, 1999, p. 197; Saavedra, 2010, pp. 111 y 146).

Los mijos menudos, que también eran cereales de primavera - aunque en cultivo de secano - fueron progresivamente expulsados a lo largo de los siglos XVII y XVIII por el milhão —el maíz- de los campos del norte al sur del país, permaneciendo residualmente en algunas comunidades de montañas del noroeste y los espacios montañosos de Extremadura, como en la Sierra de Aire, donde eran consumidos bajo la forma de papas (Ribeiro, 1981, pp. 294, 296-297; Oliveira, 2013, p. 215; Dias, 1993, p. 105). La comarca de Alcobaça no fue una excepción a esta alteración de cultivos, la cual llevaría a Fray Manuel de Figueiredo a declarar en 1787 que «não há nesta comarca milho branco miúdo, nem do amarelo chamado painço» (Maduro, 2013a, p. 343).

Con la llegada del maíz, se verifica asimismo una política general de reconversión de las rentas en las instituciones señoriales portuguesas. Salvador Magalhães Mota relata para la realidad miñota el caso de un foro donde los 13 alqueires de «milhoalvo» pagados se transformaron en muy poco tiempo en 16 alqueires y un cuarto de milhão (Mota, 2006, p. 95). También Pegerto Saavedra ilustra para el caso de Galicia este cambio, con ganancias obvias para el sistema señorial, al evidenciar que la medida del maíz era dada por exceso a su favor (Saavedra, 2010, p. 121).

La transformación del tejido agrícola de la comarca de Alcobaça es puesta de relieve en un informe municipal de 1893, cuando se afirma que: «depois da extinção dos Frades tem melhorado a industria rural no aumento de mais de 200 moios de pão terçado [...] e quatro de cereaes leguminosos, tudo diminuído de matas, baldios $[\ldots] \gg{ }^{19}$. Obviando el trasfondo ideológico liberal, marcado por la aversión a las órdenes monásticas, se constata un progreso en los trabajos y faenas que conforman el grueso de las labores agrícolas y una desaparición de los terreno incultos, situación que da cuenta de la intensificación creciente que conoció la agricultura en el pasado. Otras fuentes más tardías refuerzan esta idea. En el Relatório da Sociedade Agricola do Districto de Leiria (1856), se afirma que:

«A cultura dos ceriais no districto de Leiria tem tido de 1834 para cá um aumento bastante considerável, aumento que não podemos deixar de atribuir às seguintes causas: $1^{\circ}$ Extinção dos dízimos; $2^{\circ}$ Venda dos bens nacionais e sua divizão; $3^{\circ}$ Remissão dos foros; $4^{\circ}$ Aumento da população; $5^{\circ}$ Liberdade e o socego que os povos tem governado com o acabamento da guerra civil.

19 ADL, GC, Atividades Económicas, Agricultura, cx. 8 (1834-1854), Reflexões sobre a industria agricula do Concelho de Alcobaça (18 de outubro de 1839). 
As espécies de ceriais que mais abundam e se cultivam nos concelhos pertencentes ao distrito de Leiria, são o milho, o trigo, e a cevada; cultivam-se também em menor escala o centeio, e a aveia [...] Não erraremos talvez calculando a produção do milho em relação à do trigo na proporção de doze para um.

O milho amarelo e branco são os únicos que se semeiam em todo os districto: o milho miúdo é desconhecido $»^{20}$.

La producción de maíz a mediados del siglo XIX ya es suficiente para abastecer las necesidades de la comarca. En respuesta al punto 4, afecto a la orden del 3 de julio de 1856, la municipalidad de la misma pone de manifiesto que «este concelho não importa senão algum milho pelo porto de São Martinho, em anos escassos, mas se se attender ao que é exportado d'este concelho para Rio Maior, e Cartaxo, fica equilibrado uma com outra cousa [...]» ${ }^{21}$. En el balance de producción de 1858, ese mismo concejo registra 177.500 alqueires de maíz contra 63.200 de trigo ${ }^{22}$. El predominio de la planta se agiganta, a pesar de la competencia que los arrozales prometen a partir de la década de 1840. Aun así, en 1865 la cosecha de trigo se quedará en un quinto de la de maíz, produciendo el cereal de segunda unos 400.000 alqueires ${ }^{23}$.

El arroz, cultivo de carácter capitalista al disociarse por completo de la lógica del autoconsumo, entrará en competencia con el maíz, pero pronto se advierte que satura la tierra y que sería más beneficioso intercalar ambos cultivos, de tal forma que dos o tres años de arroz darían lugar a posteriores siembras de maíz. En un arrendamiento por tres años establecido en 1860 entre el propietario de la Quinta do Pinheiro, en Maiorga, y un labrador da Alcaidaria dos Milagres, en Leiría, de una hacienda en la citada Maiorga, a cambio de una renta de 230 alqueires de maíz/año y una séptima parte de la cosecha de arroz, se determina que al final del contrato dicho labrador deje la tierra preparada para ser sembrada con maíz ${ }^{24}$. La alternancia de estos cultivos estará a la orden del día hasta la prohibición definitiva de los arrozales en el distrito de Leiría, el 4 de mayo de 1871, con el fin de evitar los repetidos brotes de malaria que se daban en la zona ${ }^{25}$.

$20 \quad$ O Leiriense, 190, 7 de maio de 1856.

21 Biblioteca Municipal de Alcobaça, lv. 11 dos Acórdãos das Sessões da Câmara Municipal de Alcobaça, fl. 54, 13 de fevereiro de 1857.

22 ADL, GC, Atividades Económicas, Agricultura, cx. 9 (1854-1860).

23 ADL, GC, Atividades Económicas, Agricultura, cx. 10 (1860-1865).

$24 \quad$ ADL, $C N A, 9^{\circ}$ of., lv. 21, fl. 88, 1 de maio de 1860.

25 En 1870, el Vizconde de Chanceleiros, en calidad de Ministro de Obras Públicas, publica dos decretos prohibiendo los arrozales en los concejos de Leiría y Alcobaça. Assembleia da República, Diário da Câmara dos Dignos Pares do Reino, 14 de abril de 1882. 


\section{La alteración de la estructura pecuaria y el desarrollo del régimen estabular}

A finales del siglo XVIII, los contemporáneos nos dicen que una de las principales debilidades de la agricultura de Alcobaça era el sobreexceso de ocupación y explotación de las tierras, la cual acabará comprometiendo no sólo la producción de los rastrojos necesarios para el cultivo, sino también los espacios de pasto. Una situación ésta última que era relativamente compensada por las extensas plantaciones de olivares que había en los márgenes de la Sierra de Candeeiros, ya que permitían deambular y alimentarse al ganado ovicaprino (Maduro, 2013a, p. 338). Esta reducción de los incultos para fines agrícolas es registrada también por Pegerto Saavedra en la Galicia del siglo XVII, dando lugar así a la disminución de los rebaños (Saavedra, 1999, pp. 83 y 87). Al respecto, esos mismos contemporáneos explicitan que faltaban «na comarca prados, fenos, ervas de lameiros e lucernas», lo que reducía mucho el tamaño de la cabaña ganadera en régimen de pastoreo (Maduro, 2013a, pp. 338 y 343). Un diagnóstico que se verá reforzado años más tarde en el informe realizado por la Sociedade Agrícola del distrito de Leiría en 1856:

«Em geral o distrito não tem prados propriamente ditos. As restevas, e as charnecas são os recursos únicos dos possuidores de rebanhos. Algumas sementeiras de centeio, cevada, ou alimpas, feitas para serem ceifadas em verde, e deixarem o campo liberto para a sementeira do milho e feijão; algumas milharadas semiádas depois da ceifa do trigo: e em poucas localidades o trevo da flor vermelha (da espécie anual) semiado na arrenda dos milhos - tais são os únicos modos de prover a subsistência verde dos gados cavalar, e vacum do distrito.

Resulta d'este sistema uma grande abundância d'erva nos princípios da primavera, e uma falta excessiva de todo e qualquer pasto no resto do ano. As palhas escaceiam igualmente. Os fenos são inteiramente, ou quazi inteiramente desconhecidos» ${ }^{26}$.

Las tierras comportaban solamente un cultivo, pudiendo, no obstante, soportar adicionalmente el de forraje para los animales de yugo y crianza, pero esto sólo sucedía en las tierras destinadas al maíz. En las dedicadas a huerto y viña se imponían en cambio restricciones a las siembras de «pão branco para seco», dando, sin embargo, libertad a las de trigo, centeno o cebada, siempre y cuando fuesen segadas o cortadas antes de espigar, o sea, antes de ser utilizadas como alimento para el ganado (Maduro, 2013a, p. 339). 
Para conservar ese ganado, los grandes propietarios incluían en las cláusulas contractuales de los arrendamientos el sustento de los animales. En el arrendamiento por nueve años de la Quinta de São José en Alfeizerão, realizaba en 1831, la pensión anual contemplaba no sólo el pago anual de 700.000 réis, 5 moyos de cebada, 1 moyo de maíz, 12 alqueires de alubia y 24 carretadas de paja, sino también la obligación de los arrendadores:

«conservarem a raça dos mesmos gados tanto vacas como Egoas, e Bois de canga e touros e a deixarem as malhadas dos gados no mesmo estado em que as acharam e deixarem tantos quantos palheiros lhes entregarem cheios de palhas de todas as qualidades, deixarem as terras de milhos serôdios assim como se lhes entregaram nas mesmas ou noutras terras com pasto reservado para o gado de trabalho» ${ }^{27}$.

En el universo campesino se constata una mayor difusión del ganado bovino utilizado en la tracción o el uso del yugo de labranza. Según los datos de la estadística agrícola de 1854, el distrito de Leiría disponía de unos 1.650 efectivos caballares y 1.327 mulares contra 16.616 bovinos. Un desequilibrio que persiste al analizar el caso de la comarca de Alcobaça, donde el ganado vacuno se situaba en torno a los 2.000 animales —el 12\% de los efectivos del distrito-, correspondiendo al caballar 132 (el $8 \%$ ) y al mular 105 (el 7,9\%) 28 . El Recenseamento Geral de Gados de 1870 ofrece en Alcobaça una progresión de más de $100 \%$ en las reses bovinas, estimándose en ese año la existencia de un total aproximado de 4.150 cabezas. Por su parte, en 1920, el ganado bovino muestra ya una tendencia a estabilizar su número. El municipio tiene ahora unas 5.877 reses: 2.859 bueyes, 1.851 vacas, y 1.167 becerros y terneros. En este contexto, la parroquia de Alfeizerão toma ahora la delantera en lo que respecta a los bueyes de carne y de yugo, con 1.176 animales (el 41,1\% del total de los efectivos), mientras que en las feligresías de Pataias y Cela las vacas lecheras y de trabajo alcanzan los 982 animales (53\% de los efectivos), en las parroquias (Natividade, 1922, pp. 127-128). En relación con ello, la difusión a partir de mediados del siglo XIX de las «mutuas» de ganado bovino en este espacio dominado por el maíz refuerza esta evidencia estadística (Maduro, 2014, pp. 10-11).

Este ganado se sustentaba con espigas y hojas secas de maíz y alubias, cebada y avena. El cultivo de la planta, precedido de la cebada, ayudó a compensar la falta de prados naturales y permitió mantener el ganado estabulado a lo largo del año, lo que acabó por beneficiar a la agricultura a través de la producción de estiércol. Esta es una realidad que los estudios agrarios han constatado tanto en Portugal como

ADL, $C N A, 4^{\circ}$ of., lv. 35, fls. 39-40, 6 de fevereiro de 1831 .

O Leiriense, 181, 5 de abril de 1856. 
en la vecina Galicia (Pérez García, 1990, p. 94; Eiras Roel, 1998, pp. 53-54; Neto, 2010, p. 266). Ante esto, es obvio pues que la nueva relación que se evidencia entre la crianza de ganado y el trabajo agrícola facilitó la intensificación de la producción (Ardit, 2007, p. 66).

En cuanto al ganado porcino, y regresando a Fray Manuel de Figueiredo, sabemos que hacia 1787 en la zona: «há porcos bastantes criados com ervas, grainhas, bagaço de uvas, agoas de farelos e sevadas, com boletas, milhos, aboboras de muitas espécies» (Maduro, 2013a, p. 346), aunque también sabemos que el monasterio procedía a importar algunos animales del Alentejo y las Beiras para su ceba y reproducción ${ }^{29}$. La ración alimentaria de los animales estabulados o semi-estabulados era bastante diversificada. En su régimen entraban cereales, leguminosas secas, frutas verdes y secas, y tubérculos, entre otros géneros y productos. Es expresiva la información que consta en la estadística agrícola del municipio de Alcobaça en 1865, donde se muestra que de la producción de unos 35.000 alqueires de patata se dedicaban 13.000 al engorde de los cerdos (37,1\%); de 4.050 alqueires de habas unos 300 a lo mismo (7,4\%); de 500 alqueires de guisantes unos 200 (40\%); y de los 670 alqueires de judías unos 100 $(14,9 \%)^{30}$. Por su parte, la cebada contribuía con 13.000 alqueires y el maíz con 800 . Asimismo, los cerdos también eran alimentados con el bagazo de la aceituna, producto que era salado y se compactaba en $\operatorname{los}$ silos $^{31}$.

Las aves de corral, cuando eran jóvenes, se sustentaban con salvados amasados. Ya en la fase adulta, su dieta contemplaba además restos de granos de las eras y molinos, semillas de uvas, algo de maíz, hortalizas y toda suerte de restos. Es más, en las escrituras de arrendamiento de los molinos se ponía incluso como condición la entrega de alqueires con los restos del cribado, también utilizados en siembras para verde, y cambeiras, polvillo de harina impropio para la elaboración del pan, que se daba a las aves o se mezclaba en la comida de los $\operatorname{cerdos}^{32}$.

\section{El maíz en la alimentación humana}

Tal y como nos refiere Vitorino Magalhães Godinho, con el maíz «traçam-se paisagens novas, os homens alimentam-se melhor e de maneira mais variada» (Godinho, 1983, p. 23). Inicialmente, su dieta alimentaria se volvió más rica y diversa

\footnotetext{
29 ANTT, Mosteiro de Alcobaça, (en adelante MA), Livro das Despesas do Convento de Alcobaça, $\mathrm{n}^{\circ}$ 5 (1747-1750), mç. 5, cx. 132

30 ADL, GC, Atividades Económicas, Agricultura, cx. 10 (1860-1865).

31 ANTT, MA, Livro da Celeiraria, ou da Despesa do R. P. Fr. Paulo de Brito, $\mathrm{n}^{\circ} 1$ (1717-1720), mç. 5, cx. 132 (janeiro de 1719).

32 ADL, $C N A, 10^{\circ}$ of., lv. 59, fls. 26-27, 8 de janeiro de 1873.
} 
señalando un antes y un después la llegada de la planta del Nuevo Mundo (Braga, 2015 , p. 172). Sus ventajas productivas y calóricas hicieron que las gentes se estabilizasen en el espacio, permitiendo que un pequeño pedazo de tierra diese sustento a una familia completa, con lo que, por esta vía, se aumentaba la tradicional renta señorial que cobraban las grandes instituciones señoriales (Tabla 2).

Entre las clases populares, el nuevo y prolífico cereal pronto ocupó el lugar del trigo en toda suerte de mezclas para el pan cocido, asumiendo el pan de maíz, conocido como broa, la preferencia (Ardit, 2007, p. 59). La broa sumergida en jarras de aceite era el alimento principal de los maestros y ayudantes lagareros durante la fabricación del aceite, entrando este producto en las «comedorías atribuidas a estos oficiales»" ${ }^{33}$. Henriques Fonseca, en su obra Âncora Medicinal, señala que el maíz «he frio e seco como o centeyo, coze-se com dificuldade, e he menos nutriente, sendo que as pessoas, que se criarão com milho, pela familiaridade que tem com a natureza, se nutrem muyto bem com elle» (Fonseca, 1731, p. 93). La espiga de maíz también era apreciada asada en la brasa y los molinillos caseros permitían a los campesinos utilizar su harina para las gachas. Y pese a su elevado consumo, la pelagra, asociada a una dieta pobre y monótona de maíz, fue evitada en la Península Ibérica gracias a su asociación alimentaria con las alubias (Eiras Roel, 1998, pp. 48-50; Ferrières, 2002, p. 357).

Tabla 2. Población de las villas de los cotos del área de cultivo del maíz

\begin{tabular}{|l|c|c|c|c|c|c|c|c|}
\hline Parroquias & \multicolumn{2}{|c|}{ Recuento de 1721} & \multicolumn{2}{c|}{ Recuento de 1732} & \multicolumn{2}{c|}{ Censo de 1801 } & \multicolumn{2}{c|}{ Censo de 1864} \\
\hline & Hogares & Habitantes & Hogares & Habitantes & Hogares & Habitantes & Hogares & Habitantes \\
\hline Alfeizerão & 70 & - & 280 & 702 & 270 & 1127 & 435 & 1842 \\
\hline Cela & 113 & - & 390 & 1298 & 389 & 1585 & 510 & 2449 \\
\hline Maiorga & 107 & - & 145 & 523 & 173 & 619 & 214 & 916 \\
\hline Pederneira & - & - & 420 & 1374 & 734 & 2877 & - & - \\
\hline
\end{tabular}

Por su parte, las clases privilegiadas no se adhirieron a la novedad y continuaron priorizado el consumo de pan blanco. Frente a él, el pan de trigo campesino, consumido antes de la llegada del maíz, era un pan oscuro, puesto que la tasa de cribado era débil, por lo que asumía el aspecto de un pan integral (Gonçalves, 2000, p. 23). $\mathrm{Y}$ es que el color de los alimentos tenía en la mentalidad de la época implicaciones sociales. Así, por ejemplo, se entendía que el pan blanco, propio de las clases altas, se hallaba en sintonía con los vinos blancos y claretes delicados, mientras que las clases bajas necesitaban de alimentos que compensasen el esfuerzo físico cotidiano, caso del pan oscuro y los vinos rojos, cargados o retintos, astringentes y corpóreos (Flandrin y Montanari, 2001, pp. 202-203).

33 ANTT, MA, Livro de Despesa do Mosteiro de Alcobaça, $\mathrm{n}^{\circ}$ 2, (1729-1732), mç. 5, cx. 132. 


\section{Conclusión}

En las tierras de la comarca de la Alcobaça el cultivo del maíz señala, a tenor de la mutación que experimentó el paisaje y del incremento de la productividad, el último gran impulso dado en materia agrícola durante el Antiguo Régimen. Expresa pues el refuerzo que conoce la capacidad de mercantilización de la economía y anuncia la aparición de un nuevo complejo agropecuario. Si bien los monjes cistercienses habían apostado también por la difusión del olivar en la extensa y árida planicie que bordea la Sierra de Candeeiros, lo cierto es que los cambios en la reforma del espacio agrario, la innovación hidrotécnica y la intensificación agrícola están aquí íntimamente asociadas al cultivo del maíz americano. Asistimos así a una lucha permanente del hombre para garantizar las condiciones de cultivo en los campos pantanosos del litoral, fruto de las incursiones de las mareas, los torrentes repetidos o las inundaciones provocadas por el cierre del espigón marítimo.

El maíz de regadío además de humanizar el paisaje, monopolizó el espacio agrícola, expulsando los pinares, robledales y demás bosques a las laderas escarpadas, substituyendo, o incluso eliminando, los cereales tradicionales y creando nuevas asociaciones de cultivos, caso de la supresión de los prados de pasto para el ganado mayor y la justificación de la barrera forestal de pinares en la costa al objeto de bloquear el avance de las dunas cara al interior. Asimismo, patrocinó una abundancia desconocida de otras plantas, lo que facilitó la expansión demográfica y el poblamiento del territorio, y redefinió a todos los niveles las relaciones entre la agricultura y la ganadería. $\mathrm{Al}$ respecto, el pasto de los rebaños fue transferido a las áreas más serranas y estériles del dominio señorial, al tiempo que la planta facilitó la estabulación e hizo crecer el número de efectivos bovinos, lo cual, no sólo contribuyó al incremento del abonado, compensando así los efectos que a este nivel creaba la reducción de los incultos donde se recogían rastrojos, sino que contribuyó a generalizar el trabajo en el campo con instrumental pesado de tracción.

En suma, a su nivel, y en el marco de una economía señorial, el cultivo del maíz en la comarca de la Alcobaça constituyó una revolución técnica, productiva y agrícola de primer orden. 


\section{Bibliografía}

Almeida, Luís Ferrand de (1995), Páginas Dispersas. Estudos de História Moderna de Portugal, Coimbra, IHES/FLUC.

Ardit, Manuel (2007), "La Historia Rural de la España Oriental durante la Edad Moderna: un estado de la cuestión”, Studia historica. Historia Moderna, 29, pp. 47-82.

BAтн, Bernard (1984), História Agrária da Europa Ocidental, Lisboa, Editorial Presença.

Barbosa, Pedro, Moreira, Maria da Luz (2006), Seiva Sagrada. A Agricultura na Região de Alcobaça. Notas Históricas, Alcobaça, Associação dos Agricultores da Região de Alcobaça.

BECKFORD, William (1997), Alcobaça e Batalha. Recordações de uma Viagem, Lisboa, Vega.

BoAventura, Fr. Fortunato de (1827), Historia Chronologica e Critica da Real Abadia de Alcobaça, Lisboa, Na Impressão Regia.

BrAGA, Isabel Drumond (2015), “A mesa conventual e os sabores da América”, en Ribeiro, Cilene et Soares, Carmen (coords), Odisseia de Sabores da Lusofonia, Coimbra, Imprensa da Universidade de Coimbra-Editora Universitária Champagnat, pp. 169-303.

Caldas, Eugénio de Castro (1998), A Agricultura na História de Portugal, Lisboa, E.P.N.

Cardoso, P. Luiz Cardoso (1751), Diccionario Geografico, Lisboa, Regia Officina Sylviana da Academia Real, tomo II.

CARvalho, Herculano de (1953), “Coisas e Palavras: Alguns problemas etnográficos e linguísticos relacionados com primitivos sistemas de debulha na Península Ibérica", Separata da Biblos, XXIX, pp. 1-365.

CORDEIRO, João (2015), Voltar ao rio para (re)descobrir a porta de Alcobaça para o mar. Uma proposta para o território do rio Alcoa na antiga Lagoa da Pederneira, Coimbra, FCTUC.

Costa, António Carvalho da (1712), Corografia portugueza, e descripça topografica do famoso reyno de Portugal, Lisboa, tomo III.

DiAs, Jorge (1993), Estudos de Antropologia, Lisboa, Imprensa Nacional-Casa da Moeda, vol. II.

Dias, Jorge, Oliveira, Ernesto Veiga de, Galmano, Fernando (1994), Espigueiros Portugueses, Lisboa, Publicações Dom Quixote.

EIRAS RoEl, Antonio (1998), "Los productos alimentarios de ultramar en la agricultura de los países mediterráneos”, Obradoiro de Historia Moderna, nº 7, pp. 27-88. 
EstABRoOK, George (1998), "Maintenance of Fertility of Shale Soils in a Tradicional Agricultural Systems in a Central Interior Portugal”, Journal of Ethnobiology, 14, 1, pp. 15-33.

FARIÑA, Isolina (1999), "La producción agraria de la Galicia interior a finales del Antiguo Régimen: Dos comarcas de Ourense”, Historia Agraria, 18, pp. 181-199.

FERrIÈrES, Madeleine (2002), Histoire des peurs alimentaires du Moyen Âge à l'aube du XX siècle, Paris, Éditions du Seuil.

Flandrin, Jean-Louis, Montanari, Massimo (2001), História da Alimentação. 2. Da Idade Média aos tempos actuais, Lisboa, Terramar.

FORNI, Gaetano (1993), «Les six revolutions technologiques qui ont caracterise l'evolution de l'agriculture traditionelle euro-mediterraneenne», en Ramos, Pilar (coord.), Primeras Jornadas Internacionales sobre Tecnologia Agrária Tradicional, Madrid, Ministerio de Cultura, pp. 257-266.

Freire, António de Oliveira (1739), Descripçao Corográfica do Reyno de Portugal, Lisboa, Na oficina de Miguel Rodrigues.

GARCÍA, Eduíno Borges (1986), “Área Cultural de Alcobaça”, História, 95, pp. 50-66.

Godinho, Vitorino Magalhães (1983), Os Descobrimentos e a Economia Mundial, Lisboa, Editorial Presença, vol. IV.

GOMES, Saul (coord.) (2016), 500 anos da outorga dos forais do concelho de Alcobaça, Alcobaça, Câmara Municipal de Alcobaça.

GonçAlves, Iria (2000), "Do Pão Quotidiano nas Terras de Alcobaça (séculos XIV e XV)", en Actas Cister, Espaços, Territórios, Paisagens, Lisboa, Instituo Português do Patrimonio Arquitectónico, vol. I, p. 23-33.

HeErs, Jacques (1965), O Trabalho na Idade Média, Lisboa, Publicações Europa - América.

Henriques, Francisco Fonseca (1731), Ancora Medicinal, Lisboa, Na Officina de Miguel Rodrigues.

KInSEY, William Morgan (1829), Portugal Illustrated, London, Published by the author.

LARCHer, Tito (1907), Dicionário Biográfico, Corográfico e Histórico do Distrito de Leiria, Leiria.

Lima, Luis Caetano de (1734), Geografia Histórica de Todos os Estados Soberanos da Europa, Lisboa, Na Officina de Joseph Antonio da Sylva, tomo 3.

Macedo, Duarte Ribeiro de (1817), Obras inéditas de Duarte Ribeiro de Macedo, Lisboa, Na Impressão Regia.

Maduro, António Valério (2010), “O Espaço Florestal de Alcobaça nos séculos XVIII e XIX”, Revista Portuguesa de História, 41, pp. 31-57. https://doi. org/10.14195/0870-4147_41_2. 
Maduro, António Valério (2011), Cister em Alcobaça. Território, Economia e Sociedade (séculos XVIII-XX), Porto, ISMAI/CEDTUR.

Maduro, António Valério (2013a), “O Inquérito Agrícola da Academia Real de Ciências de 1787. O caso da comarca de Alcobaça", en Albuquerque Carreiras, José (ed.), Mosteiros Cistercienses. História, Arte, Espiritualidade e Património, Alcobaça, Camara Municipal, tomo III, pp. 319-354.

MAduro, António Valério (2013b), “A Prática do Associativismo Agrário e Pecuário em Alcobaça”, Associações Agrícolas, Alcobaça, Cooperativa Agrícola de Alcobaça, pp. 5-18.

MADURO, António Valério (2017), "Um retrato da paisagem florestal de Alcobaça em 1834. O Relatório do Corregedor sobre o estado das matas do extinto mosteiro", Cadernos de Leiria, 15, pp. 239-244.

Maduro, António Valério, Mascarenhas, José Manuel de, Jorge, Virgolino Ferreira (2017), "Waterplanning in Alcobaça cistercianlands", Riparia, 3, pp. 95-126.

MArques, A. H. de Oliveira (1978), Introdução à História da Agricultura em Portugal, Lisboa, Edições Cosmos.

Mota, Salvador Magalhães (2006), Cistercienses, Camponeses e Economia Rural no Minho na Época do Antigo Regime, Lisboa, Imprensa Nacional - Casa da Moeda, vol. II.

Natividade, Manuel Vieira (1916), “O Povo da Minha Terra. Notas e Registo de Etnografia Alcobacense”, Terra Portuguesa. Revista Ilustrada de Arqueologia Artística e Etnografia, pp. 17-20.

Natividade, Joaquim Vieira (1922), A Região de Alcobaça. Algumas Notas para o Estudo da sua Agricultura, População e Vida Rural, Lisboa, vol. I.

Natividade, Manuel Vieira (1960), Mosteiro e Coutos de Alcobaça, Alcobaça, Ed. de autor.

Neto, Margarida Sobral (2007), Terra e Conflito. Região de Coimbra (1700-1834), Viseu, Palimage Editores.

Neto, Margarida Sobral (2010), O Universo da Comunidade Rural. Época Moderna, Viseu, Palimage.

Oliveira, Aurélio de (2013), Terra e Trabalho. Senhorio e Gentes no Vale do Cávado durante o Antigo Regime. A Abadia de Tibães 1620-1822, Maia, ISMAI, vol. I.

Oliveira, Ernesto Veiga de, Galhano, Fernando, Pereira, Benjamim (1983), Alfaia Agrícola Portuguesa, Lisboa, Instituto Nacional de Investigação Científica.

O'NeIll, Brian Juan (1984), Proprietários, Lavradores e Jornaleiros, Lisboa, Publicações Dom Quixote. 
Pérez GarcíA, José Manuel (1990), «Le Mais dans le Nord-Ouest de la Peninsule Iberique durantl'Ancien Regime», Flaran 12. Plantes et cultures nouvelles en Europe occidentale, au Moyen Age et à l'époque moderne, Centre Culturel de l'Abbaye de Flaran, Auch, pp. 81-102.

Ribeiro, José Diogo (1928), Turquel Folclórico. Parte II. Usos e Costumes, Ed. de autor.

Ribeiro, Orlando (1981), "Milho”, Dicionário de História de Portugal, Porto, Libraria Figueirinhas, vol. IV, pp. 295-297.

RibeIro, Orlando (1986), Portugal, o Mediterrâneo e o Atlântico, Lisboa, Edições Sá da Costa.

Ribeiro, Orlando (1991), Opúsculos Geográficos - O Mundo Rural, Lisboa, Fundação Calouste Gulbenkian, vol. IV.

Ribeiro, Orlando, Lautensach, Hermann, Daveau, Suzanne (1991), Geografia de Portugal - IV - A Vida Económica e Social, Lisboa, Edições Sá da Costa.

Rocha, Rui (1998), A Viagem dos Sabores, Lisboa, Edições INAPA.

SAAVEDRA, Pegerto (1999), «Petite explotation et changement agricole à l'intérieur d'un 'vieux complexe agraire'. Les campagnes de la Galice entre 1550 et 1850», Histoire et Sociétés Rurales, 12, pp. 63-108.

SAAVEDRA, Pegerto (2010), "Trayectoria de las rentas monásticas y del sistema agrario de Galicia desde la segunda mitad del XVI a 1835", Revista Portuguesa de História, 41, pp. 105-156. https://doi.org/10.14195/0870-4147_41_5.

SALtini, Antonio (2014), "La Campagne Lombarde, Tesserachiave del Mosaico Agrario Europeo", Glocalism. Journal of Culture Politics and Innovation, pp. 1-27.

Silveira, Luís (coord.) (2001), Os Recenseamentos da População Portuguesa de 1801 a 1849, Lisboa, Instituto Nacional de Estatística, vol. I.

VALENÇA, Licínio (1927), Carta dos terrenos alagados das freguesias de Cela, Valado, Pederneira e Famalicão, Lisboa, Ministério da Agricultura, Divisão de Agrimensura.

Wateau, Fabianne. (2000), Conflitos e Água de Rega. Ensaio sobre a organização social no vale de Melgaço, Lisboa, Publicações Dom Quixote.

Wolf, Philippe (1988), Outono da Idade Média ou Primavera dos Novos Tempos, Lisboa, Edições 70. 